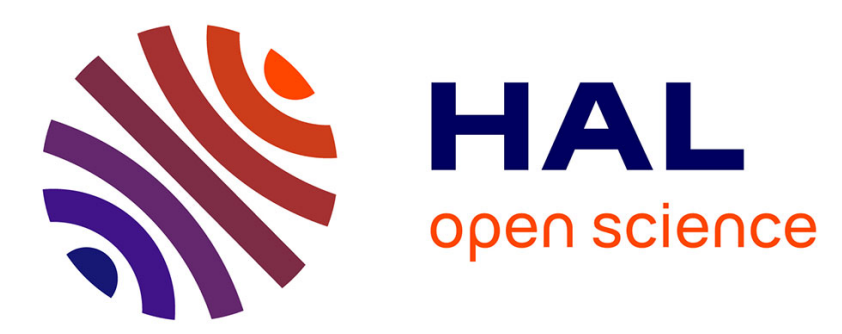

\title{
Structural and Chemical Effects of Lithium Extraction in Spinel Manganese Oxides
}

\author{
B. Ammundsen, D. Jones, J. Rozière
}

\section{To cite this version:}

B. Ammundsen, D. Jones, J. Rozière. Structural and Chemical Effects of Lithium Extraction in Spinel Manganese Oxides. Journal de Physique IV Proceedings, 1997, 7 (C2), pp.C2-1257-C2-1258. 10.1051/jp4:19972221 . jpa-00255295

\section{HAL Id: jpa-00255295 https://hal.science/jpa-00255295}

Submitted on 1 Jan 1997

HAL is a multi-disciplinary open access archive for the deposit and dissemination of scientific research documents, whether they are published or not. The documents may come from teaching and research institutions in France or abroad, or from public or private research centers.
L'archive ouverte pluridisciplinaire HAL, est destinée au dépôt et à la diffusion de documents scientifiques de niveau recherche, publiés ou non, émanant des établissements d'enseignement et de recherche français ou étrangers, des laboratoires publics ou privés. 


\title{
Structural and Chemical Effects of Lithium Extraction in Spinel Manganese Oxides
}

\author{
B. Ammundsen, D.J. Jones and J. Rozière \\ Laboratoire des Agrégats Moléculaires et Matériaux Inorganiques, ESA 5072, CNRS, \\ Université Montpellier 2, Place Eugène Bataillon, 34095 Montpellier cedex 5, France
}

\begin{abstract}
XAFS of the manganese $K$-edge in $\mathrm{LiMn}_{2} \mathrm{O}_{4}$ has allowed the chemical and structural effects of lithium extraction and reinsertion to be characterised and attributed to oxidation-reduction processes. Structural information in the experimental data at low $k$, as well as that relating to scatterers beyond the first two coordination shells, can be accurately analysed using $a b$ initio curved-wave multiple scattering simulations.
\end{abstract}

\section{INTRODUCTION}

The reversibility of lithium extraction and insertion in spinel lithium manganates can be exploited both in selective lithium sorption from aqueous solutions [1] and in nonaqueous rechargeable batteries [2]. Depending on the oxidation state of manganese in the parent compound, the process in aqueous solution may occur both through electron transfer and by exchange with protons $[1,3]$. Manganese $K$-edge XAFS allows the chemical and structural changes accompanying lithium extraction and reinsertion to be compared for materials in which one or the other of these mechanisms dominates [4]. Here we summarise results for the mixed valence spinel $\mathrm{LiMn}_{2} \mathrm{O}_{4}\left(\mathrm{LiMn}^{\mathrm{II}} \mathrm{Mn}^{\mathrm{IV}} \mathrm{O}_{4}\right)$, and investigate the potential of $a b$ initio curved-wave multiple scattering calculations to allow the experimental data to be analysed beyond a simple two-shell model.

\section{EXPERIMENTAL}

$\mathrm{LiMn} \mathrm{O}_{4}$ was prepared by heating a ground mixture of lithium and manganese carbonates to $800^{\circ} \mathrm{C}$ for $24 \mathrm{~h}$ in air. Lithium extraction to give $\lambda-\mathrm{MnO}_{2}$ was achieved by stirring in $0.2 \mathrm{M} \mathrm{HCl}$ for $72 \mathrm{~h}$, and lithium reinsertion in $0.1 \mathrm{M} \mathrm{LiOH}$ for $120 \mathrm{~h}$.

$\mathrm{X}$-ray absorption data were recorded in transmission mode at $77 \mathrm{~K}$ for samples diluted in boron nitride and pressed as Nujol mulls between Parafilm windows, on the EXAFS 3 spectrometer at LURE-DCI with He/Ne-filled ionisation chambers and a Si 311 double monochromator. Data analysis was perfomed by standard procedures described elsewhere $[4,5]$. Ab initio curvedwave multiple scattering $\chi(k)$ and $\mu(E)$ spectra were calculated with FEFF6 [6], using the Hedin-Lundqvist photoelectron selfenergy with a $1.5 \mathrm{eV}$ correction to the imaginary part. Clusters of $\sim 8 \AA$ radius, comprising $\sim 250$ atoms in 24 coordination shells, were constructed for calculation of atomic scattering potentials. Scattering terms up to third order and with path lengths up to $18 \AA$ were considered, and those contributing a mean-path amplitude greater than $2.5 \%$ of that of the first shell maximum were included in the final calculation of the spectra.

\section{RESULTS AND DISCUSSION}

\subsection{Chemical and Structural Effects in the Spectra}

Figure I compares absorption edge spectra for $\mathrm{LiMn}_{2} \mathrm{O}_{4}$, its lithium-extracted $\lambda-\mathrm{MnO}_{2}$ product, and the lithium-reinserted sample. Lithium extraction results in a global shift of the absorption edge by $-3 \mathrm{eV}$ to higher energy. The preedge " $1 \mathrm{~s}->3 \mathrm{~d}^{\text {" }}$ structure also evolves from a mixed $\mathrm{Mn}^{\mathrm{Il} / \mathrm{/V}}$ form to a welldefined doublet typical of $\mathrm{Mn}^{\mathrm{IV}}$ oxides [7]. Interatomic distances determined from the EXAFS show contraction of the Mn-O distance from 1.93 to $1.90 \AA$, and of $\mathrm{Mn}-\mathrm{Mn}$ distances from 2.90 to $2.84 \AA$. The data also show a large decrease in the Debye-Waller factors when lithium is extracted, which may be atributed to removal of a static distribution of interatomic distances when the $\mathrm{Mn}^{\mathrm{mI} / \mathrm{N}}$ compound is oxidised. The presence of $\mathrm{Mn}^{\mathrm{III}}$ (a Jahn-Teller ion) in the lithium-form material introduces some local tetragonal distortion not detected by diffraction experiments which reflect only the long range cubic symmetry.

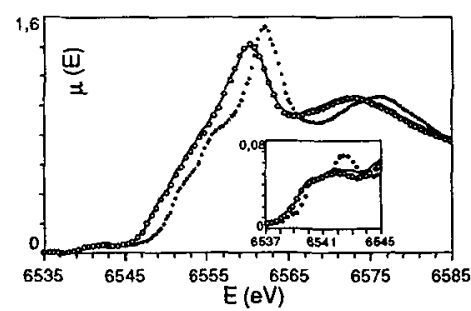

Figure 1: Edge spectra for $\mathrm{LiMn}_{2} \mathrm{O}_{4}$ (line), and its products after lithium extraction (dots) and reinsertion (circles). Insert; pre-edge peaks.

The reversibility of the redox process is seen from the complete restoration of the spectrum of the original parent material when lithium is reinserted, including the chemical shift of the absorption edge, the pre-edge structure, interatomic distances and higher Debye-Waller factors. 


\subsection{Multiple Scattering Data Analysis}

Figure 2a compares the Fourier-transformed experimental EXAFS data for the $\lambda-\mathrm{MnO}_{2}$ product of $\mathrm{LiMn}_{2} \mathrm{O}_{4}$ with $a b$ initio simulations for single scattering only and with multiple scattering terms included.

Both single and multiple scattering calculations satifactorily reproduce the experimental spectrum up to $\sim 5 \AA$. Owing to the high symmetry of the spinel structure, the essential structural information can be derived from the data in the first two intense peaks in the Fourier transform. Good agreement with the experimental data Fourier-isolated over these two peaks can be achieved by curve-fitting a simple single scattering model using only two unique paths, giving six oxygens at $1.904 \AA$ and six manganese at $2.841 \AA$. Calculations predict that three multiple scattering paths with $R_{\text {eff }}$ between 3.15 and $3.35 \AA$ may also contribute to the data in this $R$ range, particularly as multiple scattering paths are generally phase-shifted by $0.3-0.4 \AA$ per scatterer to smaller $R[6]$. Two of these paths correspond to double scattering within the first oxygen coordination shell, and the third corresponds to a triangular path involving both a first shell oxygen atom and a second shell manganese. However, while including these paths in the curve-fitting procedure improved the agreement between experimental and calculated $k$-space XAFS, particularly at low $k$ (Figure $2 \mathrm{~b}$ ), it did not affect the structural parameters obtained for the $\mathrm{Mn}-\mathrm{O}$ and $\mathrm{Mn}-\mathrm{Mn}$ pairs. Multiple scattering contributions to the first two shells can therefore be considered as negligible.

For $R>5 \AA$ multiple scattering terms have more significant effects on the data. In particular, the amplitudes of the Fourier peaks at $\sim 5.3$ and $\sim 8 \AA$ (twice and three times the nearest manganese neighbour distance) derive principally from forward scattering or "focusing" of the photoelectron by manganese atoms forming linear chains which cross perpendicularly to give the three dimensional cubic spinel framework. The ability of the multiple scattering model to allow data at higher $R$ to be exploited was tested by curve-fitting over the two peaks in the domain $4.5<R<6 \AA$. Attempts to fit a two-shell single scattering model, with twelve manganese at both 4.93 and $5.68 \AA$, were
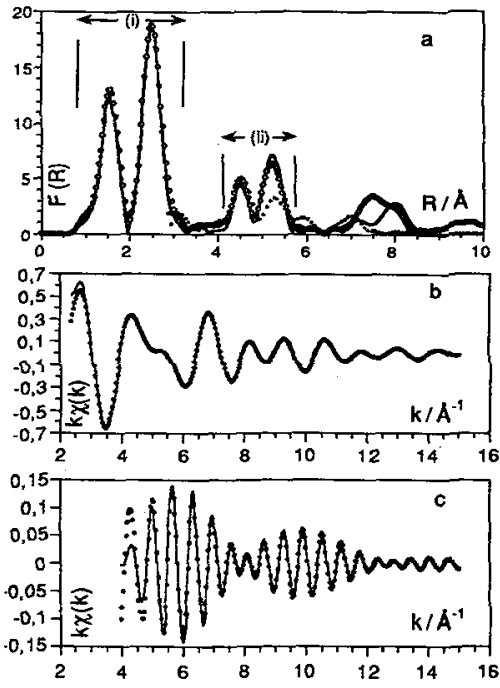

Figure 2: (a) Fourier-transformed EXAFS data for $\lambda-\mathrm{MnO}_{2}$ (circles) with single scattering (dotted line) and multiple scattering (solid line) calculations; (b), (c) multiple scattering curve fits in $k$ space to the experimental data Fourier-isolated over regions (i) and (ii) respectively.

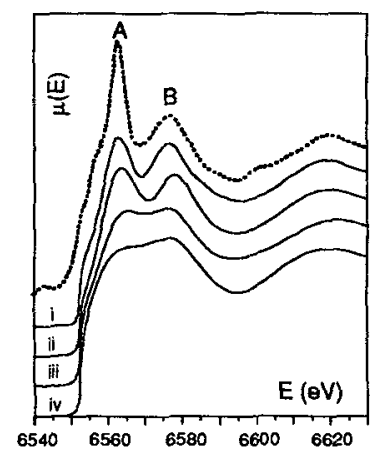

Figure 3: Experimental spectrum of $\lambda-\mathrm{MnO}_{2}$ (dots) compared with multiple scattering simulations for (i) 24 , (ii) 4 , and (iii) 2 shells, and (iv) a single scattering simulation for 4 shells. (Spectra displaced vertically for clarity). unsuccessful. Differences in the phase shifts for the first order term relating to the manganese at $5.68 \AA$, and second- and third-order terms which produce large amplitudes due to forward scattering once and twice respectively by the colinear manganese atom at $2.84 \AA$, strongly affect the EXAFS spectrum and its Fourier transformation in this range of $R$. It was therefore not possible to reproduce the experimental spectrum with only the first-order term, even with an inflated coordination number. Considerable improvement in fitting the theoretical curve was obtained by including the multiple scattering terms (Figure 2c). This simulation allowed the $\mathrm{Mn}$-Mn distances to be refined at 4.92 and $5.67 \AA$ respectively, within $0.01 \AA$ of distances determined from the radii of the first two shells.

Figure 3 compares simulations of $\mu(E)$ at the absorption edge with the experimental data for $\lambda-\mathrm{MnO}_{2}$. The simulations have been displaced $11 \mathrm{eV}$ to higher energy to correct for a difference in the absolute energy scale. The third-order calculation for the full 24 -shell cluster satisfactorily reproduces the resonance $B$ and the relative energy of the resonance $A$, although neither the full white line intensity at $A$ nor the double inflection structure in the edge itself could be reproduced. Reducing the third-order calculation to include only the first four coordination shells gives almost the same result. However both a first-order calculation over four shells and a third-order calculation over the first two shells give only a single broad resonance, and the inclusion of multiple scattering to the third and fourth shells is therefore essential to reproduce the experimental data. These shells consist of oxygen atoms at distances $3.3-3.5 \AA$ from the central manganese. The near edge structure is therefore found to derive principally from highly degenerate multiple scattering paths involving these oxygen atoms, rather than manganese shells.

\section{References}

[1] Feng Q., Miyai Y., Kanoh H. and Ooi K., Langmuir 8 (1992) 1861-1867 and references therein.

[2] Thackeray M.M., de Kock A., Rossouw M.H., Liles D.C., Bittihn R. and Hoge D., J. Electrochem. Soc. 139 (1992) $363-366$.

[3] Ammundsen B., Burns G.R., Jones D.J. and Rozière J., Chem. Mater. 7 (1995) 2151-2160.

[4] Ammundsen B., Burns G.R., Jones D.J. and Rozière J., Chem. Mater. 8 (1996) in press.

[5] Michalowicz A., "EXAFS pour le Mac", Logiciels pour la Chimie (Société Française de Chimie, Paris, 1991) pp. $102-103$.

[6] Zabinsky S.I., Rehr J.J., Ankudinov A., Albers R.C. and Eller M.J., Phys. Rev. B 52 (1995) 2995-3009.

[7] Manceau A., Gorshkov A.I. and Drits V.A., Am. Miner. 77 (1992) 1133-1143. 